\title{
A interface entre o trabal ho do agente comunitário de saúde e do fisioterapeuta na atenção básica à saúde
}

\author{
Interface between the work of the community health agent \\ and physiotherapist in the basic health care
}

Liliany Fontes Loures $^{1}$

M aria Cecília de Souza Silva ${ }^{2}$

\footnotetext{
${ }^{1}$ Fundação deApoio ao Hospital Universitário, UFJF. Rua Catulo

Breviglieri 46, Santa

Catarina. 36036-110 Juiz deFora MG.

lilianyfl@yahoo.com.br

${ }^{2}$ Clínica de Fisioterapia

Neuro \& Fisio.
}

Abstract The study is intended to identify the actions of the physiotherapist and community health agent in the context of the integration of their performances in the basic health care. A systematic review was performed with the purpose of knowing what arethese performances, and then list them. The interest came from the "Supervised Training in the Primary Health Care" and the observation of their acts. From a law review and updated scientific works related to this subject, we noted that both, community health agent and physiotherapist, are important professionals in the composition of a health team, once they contribute to the qualification of the health actions among the community and the effectiveness of an universal, integral and equitablehealth system. Lastly we found that there is an interaction between these professionals and integration among their activities.

Key words Community health agent, Physiotherapy, Basic health care, Professional performance, Professional interaction, Systematic review
Resumo 0 estudo tem o objetivo de identificar as ações do fisi oterapeuta e do agente comunitário de saúde na perspectiva da integração de suas atuações na atenção básica à saúde. Realizou-se uma revisão sistemática com o propósito de conhecer quais são essas atuações e, posteriormente, relacioná-las. 0 interesse surgiu durante o "Estágio Supervisionado em Atenção Primária à Saúde" e da observação de suasatuações. A partir da revisão de legislações e de trabalhos científicos atualizados acerca do assunto, verificou-se que tanto 0 agente comunitário de saúde quanto o fisioterapeuta são profissionais importantes na composição de uma equipe de saúde, pois contribuem à qualificação das ações de saúdejunto à comunidadee à efetividade de um sistema de saúde universal, integral e equitativo. Ao final, constatou-se que há uma interação entre esses profissionais e uma integração entre suas atividades.

Palavras-chave Agente comunitário de saúde, Fisioterapia, Atenção básica à saúde, Atuação profissional, Interação profissional, Revisão sistemática 
Introdução

A crescente valorização da atenção básica à saúde (ABS) estimula o aprofundamento do conhecimento e entendimento da assistência prestada à população neste nível, com o qual tivemos um contato mais próximo durante 0 estágio curricular, realizado em duas unidades básicas de saúde (UBS), na cidade de Juiz de Fora (M G), em que havia a atuação do fisioterapeuta.

O estágio se processou em U BS com características distintas. Enquanto uma implantava o Programa Saúde da Família (PSF), com a participação direta do agente comunitário de saúde (ACS), a outra não dispunha do programa nem da presença desse profissional. A participação direta do ACS nas atividades desempenhadas pela fisioterapia na UBS nos impressionou e, a partir dessa experiência, surgiu o interesse de estudar as ações do ACS e do fisioterapeuta.

A ABS, primeiro nível de atenção à saúde segundo o modelo adotado pelo Sistema Único de Saúde (SUS), é definida como "a porta de entrada", o contato primário e preferencial da população com os profissionais da saúde. É guiada pelos princípios defendidos pelo SUS - universalidade, integralidade e equidade - , enfatiza o trabalho em equipeeengloba um conjunto de ações de caráter individual e coletivo, que envolvem promoção da saúde, prevenção de doenças, diagnóstico, tratamento e reabilitação $0^{1-4}$.

A partir da década de noventa, em busca da reorientação, expansão e qualificação da ABS, 0 Ministério da Saúde(MS) iniciou a implantação do Programa deAgentes Comunitários de Saúde (PACS) e do PSF 5 .

Em 1991, o PACS foi institucionalizado com uma função prioritariamente materno-infantil ${ }^{6} \mathrm{e}$ sua implantação foi considerada inovadora, pois estimulava a participação ativa de agentes sociais na execução de políticas públicas desaúde, iniciando a vinculação da população com os serviços?.

O PSF, criado em 1994, foi operacionalizado mediante a implantação de equipes multiprofissionais nas U BS 5 . Cada equipe do PSF écomposta, no mínimo, por um médico, um enfermeiro, um auxiliar de enfermagem e de quatro a seis agentes comunitários de saúde (ACS), sen do que o ACS foi inserido pelo PACS ${ }^{8}$. Diferentemente dos outros integrantes da equipe, o ACS é, obrigatoriamente, oriundo da comunidade, o que remete a aspectos de solidariedade, liderança e conhecimento da realidade social que o cerca, evidenciando um perfil mais social do que burocrático ou técnico ${ }^{7,9}$.
Entretanto, somente em 1997, o M S, através da Portaria $\mathrm{n}$ - 1.886/GM , aprovou as normas e diretrizes para a regulamentação da implantação e operacionalização do PACS e do PSF ${ }^{10}$. Em seguida, com a crescente ampliação das ações do ACS, surgiu a necessidade de reconhecer sua identidade profissional e seus direitos trabalhistas e sociais. Isto acarretou na edição do Decreto no 3.189/99, que fixou as diretrizes para o exercício da atividade de agente comunitário de saúde ${ }^{11} \mathrm{e}$, em 2002, na criação da profissão agente comunitário de saúde, através da Lei $n$ ㅇ 10.50712.

Diferentemente do ACS, o fisioterapeuta não é um profissional que integra a equipe mínima proposta para o PSF, mas vem conquistando seu espaço desde a última década, podendo integrar uma equipe multiprofissional de apoio às equipes de Saúde da Família de acordo com as necessidades locais do município ${ }^{13}$.

Em decorrência das grandes transformações demográficas eepidemiológicas, ecom aimplantação do PSF, percebeu-se a necessi dade e a importância da inserção do fisioterapeuta na equipe, visando maior prevenção de doenças, promoção e manutenção da saúde, melhorando, assim, a qualidade de vida da comunidade ${ }^{14}$.

Portanto, estudar a interface do trabalho do ACS e do fisioterapeuta faz-se relevantepela possível relação existente entreesses profissionais na ABS, etambém pelas repercussões que a existência desta relação poderão representar no contexto da intervenção em uma UBS, onde se busca a integração das ações de cada profissional para o alcance de um objetivo maior: a saúde da população usuária.

Diantedo exposto, esteestudo pretendeidentificar as ações do fisioterapeuta e do ACS, na perspectiva da integração das atuações destes profissionais na ABS da população. No entanto, não se pretende discutir o caminho percorrido pela fisi oterapia na busca de sua inser ção naABS, sendo este um assunto amplo eum processo que ainda está em andamento etem sido amplamente debatido.

\section{Metodologia}

Este trabal ho é uma revisão sistemática sobre as atividades desen volvidas pelo fisioterapeuta e pelo agente comunitário de saúde na ABS.

Iniciou-se este processo realizando uma busca de referências com os unitermos "agente comunitário de saúde", "atividades do agente comunitário de saúde", "fisioterapia na atenção 
primária à saúde", "fisioterapia na atenção básica à saúde", "fisioterapeuta no Programa Saúde da Família" e "fisioterapeuta na atenção primária", nos bancos de dados Bireme, LILACS, SciELO e Google Acadêmico, sem fazer restrições.

A busca de referências foi realizada nos meses demarço a maio, outubro enovembro do ano de 2007 e, após a busca, os documentos foram selecionados seguindo os seguintes critérios para inclusão: texto completo, publicação posterior ao ano de 2000 e possuir informações relevantes sobre os profissionais/profissões em questão.

Para seter o conhecimento da legislação, como portarias, decretos eleis, referente a estes profissionais, acessamoso endereço eletrônico do M inistério da Saúde, Conselho Federal de Fisioterapiae Terapia O cupacional eM inistério da Educação e, ainda, a Biblioteca Virtual de Saúde, na qual encontramos algumas cartilhas formuladas pelo próprio M S, e o Banco de Teses/Capes.

Todas as referências incluídas foram fichadas e avaliadas quanto à relevância para esta revisão. A pós identificarmos as ações e as intervenções próprias destes profissionais na $A B S$, relacionamos todas as atividades desempenhadas por ambos e, posteriormente, listamos e descrevemos estas atividades a fim de identificar a interface entre as ações destes profissionais.

\section{Resultados}

Foram selecionadas 35 referências que abordam a atuação do agente comunitário de saúde e do fisioterapeuta, sendo $60 \%$ (21) sobre a do ACSe $40 \%$ (14) sobre a do fisioterapeuta. E entre as referências sobre a atuação do fisioterapeuta, foram encontradas cinco que relatam uma relação entre o trabalho do ACS e do fisioterapeuta, representando $35,71 \%$.

\section{Atuação do agente comunitário de saúde}

As legislações relevantes com relação à atuação do ACS na ABS são: a Portaria no 1.886/GM de 1997, queaprova as normas e diretrizes para a regulamentação da implantação e operacionalização do PSF e do PACS ${ }^{10}$; 0 Decreto no 3.189 de 1999, que fixa as diretrizes para o exercício da atividade deagente comunitário de saúde ${ }^{11}$; a Lei no 10.507 de 2002, que caracteriza as atividades desenvolvidas e os requisitos necessários para 0 exercício desta profissão ${ }^{12}$; e a Portaria no 648/ GM de 2006, que aprova a Política Nacional de Atenção Básica, estabelecendo a revisão de dire trizes e normas para a organização da atenção básica para o PSF e o PACS4.

Além das legislações, existem as cartilhas formuladas pelo MS, as quais fazem menção ao ACS: "Saúde da Família: uma estratégia para a reorientação do modelo assistencial" ${ }^{8}$, de 1997; "Programa agentes comunitários de saúde" ${ }^{15}$, de 2001; e"Referencial curricular paracurso técnico de agente comunitário de saúde: área profissional saúde" ${ }^{\prime \prime}$, de 2004.

$\mathrm{Na}$ Portaria $\mathrm{n} 01.886 / \mathrm{GM}^{10}$, o MS estabelece as atribuições básicas dos ACS. Porém, em 2006, esta portaria foi uma das que foram revogadas pela Portaria $\mathrm{n}^{0} 648 / \mathrm{GM}^{4}$, a qual descreve as atribuições comuns a todos os profissionais que atuam naABS, sen do caracterizadas por uma atuação vinculada à saúde da comunidade, que proporcionaum atendimento humanizado eintegral e se responsabiliza pela população. Esta portaria ainda reitera as competências do ACS descritas nas legislações citadas ${ }^{11,12}$ e descreve, de forma ampla, as atribuições específicas desse profissional, sendo elas: registrar as famílias de sua microárea; estar em contato permanente com a comunidade, desenvolvendo atividades de promoção da saúde, prevenção de doen ças e vigilância à saúde, por meio devisitas domiciliares, edesenvolvendo ações educativas individuais e coletivas nos domicílios ena comunidade; manter a equipeinformada de todos os dados coletados; acompanhar, por meio de visita domiciliar, todas as famílias e indivíduos sob sua responsabilidade e orientálos quanto à utilização dos serviços de saúde disponíveis e desenvolver ações que busquem a integração entre a equipe de saúde e a comunidade.

Da mesma forma, as cartilhas ${ }^{8,9,15}$ formuladas pelo M S descrevem as atividades do ACS eas agrupam em cadastramento/diagnóstico das pessoas da comunidade; mapeamento e identificação da localização das residências das áreas de risco; realização das visitas domiciliares, caracterizadas como o principal instrumento de trabaIho dos ACS; ações junto à unidade; ações coletivas para mobilizar a comunidade, através de reuniões e encontros com diferentes grupos (gestantes, mães, pais, adolescentes, idosos, grupos de situação de risco ou de portadores de doenças comuns); atividades de prevenção de doenças e promoção da saúde, por meio de ações educativas, em conformidade com os princípios e diretrizes do SU S eações intersetoriais, como educação e cidadania/direi tos humanos.

Nogueira et al. ${ }^{16}$ apresentaram o perfil ocupacional do ACS e listaram suas atividades típicas, assim como foram descritas pelas carti- 
Ihas ${ }^{8,9,15}$. Destacaram, ainda, a importância do papel social exercido pelo ACS, ao atuar como mediador entre distintas esferas de organização da vida social.

Bornstein e Stotz ${ }^{17}$ descreveram que o papel desse profissional como mediador é uma unanimidade, tanto no que se refere à mediação entre o serviço e a comunidade como entre diferentes saberes.

Nunes et al. ${ }^{18}$ também demonstraram a função de mediador do ACS, posicionado entre a comunidade e a equipe de saúde, e o seu caráter híbrido e polifônico, marcado pelo fato de ser aquele que convive com a realidade e as práticas de saúde do bairro onde mora e trabalha e ser formado com base em referenciais biomédicos. Reconheceram, ainda, o movimento bidirecional dos ACS que, de um lado, informam à população "modos de fazer" e, de outro, fornecem aos profissionais de saúde elementos-chave para a compreensão dos problemas de saúde e necessidades da comunidade.

Os mesmos autores ${ }^{18}$ descreveram e constataram o papel de tradutor que o ACS desempe nha, mediando o universo técnico-científico específico com o saber popular. Com base nestes conceitos evidenciados por $\mathrm{N}$ unes et al. ${ }^{18}$, Silva e Trad $^{19}$ identificaram o movimento bidirecional dos ACS, e Levy et al..$^{20}$ verificaram o papel de tradutor do ACS nas comunidades estudadas.

No estudo de Levy et al. ${ }^{20}$, os ACS relataram que realizavam encaminhamentos à $U B S$, visitas domiciliares, cadastramento das famílias, trabaIho de prevenção e, ainda, um agente comunitário definiu sua atuação como sendo a de um psicólogo, de um amigo.

$\mathrm{N}$ a perspectiva do aspecto relacional dos ACS, Nunes et al. ${ }^{18} \mathrm{e}$ Fabri e Waidman ${ }^{21}$ também destacaram essa relação de amizade e confiança estabelecida pelo agente com a comunidade, a fim de melhor alcançar os seus objetivos e estabelecer o nível de aproximação necessário.

Em um estudo de caso, Friedrich ePieranto$\mathrm{ni}^{22}$ verificaram que as atividades essenciais dos ACS são as visitas às famílias cadastradas, a mobilização da comunidade de forma que esta resolva seus problemas com a equipe do PSF, a orientação quanto a medicações, a identificação deindivíduos ou famílias quenecessitem deatendimento domiciliar e de grupos educativos.

Fortes e Spinetti ${ }^{23}$ identificaram que o ACS deve estar capacitado a estabelecer relações que favoreçam o levantamento de informações sobre a saúde individual efamiliar da comunidade. Em seus relatos, os ACS definiram suas atuações como informar o usuário sobre as questões administrativas eorganizacionais dos serviços, propor medidas preventivas, facilitar o acesso e orientá-lo para a utilização adequada dos serviços de saúde.

Ferraz e Aerts ${ }^{24}$ verificaram que, entre as atividades desempenhadas pelosACS, pode-se destacar a visita domiciliar e a educação em saúde. $N$ as atividades educativas, as orientações que mais costumam prestar às famílias são referentes à higiene, ao calendário vacinal, aos cuidados com recém-nascidos, puérperas e gestantes e ao uso correto das medicações. Além disso, realizam o acompanhamento deidosos, crianças, gestantes, puérperas e grupos de risco e também auxiliam a equipe dentro das UBS.

Em um estudo com profissionais pertencentes à equipe do PSF, Pedrosa e Tel es ${ }^{25}$ destacaram que o trabal ho dos ACS estava centrado no foco domiciliar eacompanhamento dos grupos de risco, tendo eles a consciência de que trabalham com ações depromoção da saúde e preven ção de doença, desenvolvendo práticas de educação e imunização.

Silva ${ }^{26}$ percebeu quehá concordância entreas orientações do M S para o trabalho dos ACS e 0 trabalho realizado por estes profissionais nas UBS. As ações básicas de saúde desen volvidas são descritas como realizar visitas domiciliares, desenvolver atividades de educação em saúde individual ou coletiva, estimular a organização comunitária e promover reuniões de grupos para a discussão de necessidades sentidas pelos moradores de sua microárea de atuação.

Fabri e Waidman ${ }^{21}$ relataram a responsabilidadedos ACS para com sua comunidade, identificando também que esse profissional executa suas atribuições conforme foi capacitado, mas destacaram que possuem uma responsabilidade maior, não sendo apenas a de cumprir ações em saúde. O ACS tem o objetivo de manter ou meIhorar a qualidade de vida da família com a qual se compromete, a responsabilidade de buscar soluções para as necessidades detectadas.

Silva e Santos ${ }^{27}$ também verificaram que as ações dos ACS estão de acordo com o que foi delimitado pelas diretrizes governamentais. Além disso, identificaram que essas ações extrapolam as prescritas em seu leque de competências, mas as atividades educativas, descritas pelos autores como mola mestra das ações dos ACS, não são desempenhadas de maneira ampla.

Em sua conclusão, N ogueira et al. ${ }^{16}$ também destacaram que os ACS realizam tarefas que não se restringem ao campo da saúde, caracterizan- 
do-os como um trabalhador genérico, deidentidade comunitária, que tem sua atividade ancorada em um perfil social composto por sua capacidade de liderança e ajuda solidária intracomunitária, constituindo-se um trabalhador sui generis.

Fabri e Waidman ${ }^{21}$ definiram que, de todas as atribuições do ACS, a de realizar visitas domiciliares é a principal função. Afirmaram que é neste momento que ocorre o elo entre a equipee a comunidade e se iniciam todas as ações desempenhadas pela equipe de saúde, pois a família faz um vínculo com o ACS e isto a faz participar com maior interesse das ações de saúde. Dessa forma, destacaram que o ACS é o observador eo elo deinformação entre a equipee a família. Silva e Santos ${ }^{27}$ também colocaram que as visitas domiciliares são uma atividade de grande impacto no trabalho do ACS, ocupando quase que integralmente sua jornada de trabal ho.

Em seu trabalho, Zancheta et al. ${ }^{28}$ trouxeram a visão crítica e os impasses que os ACS encontram na prática de seu trabal ho, os quais restringiram sua função ao controle de doenças crônicas ou à prevenção de outras, pois se vêem impossibilitados de promover a saúde.

Silva e $\operatorname{San} \operatorname{s}^{27}$ também descreveram que há uma prevalência de atividades que reforçam 0 modelo biomédico e apontaram para a necessidade de maior engajamento em atividades de promoção de saúdee prevenção de doenças, pois no conjunto das competências do ACS essas atuações são importantes.

Já Fabri eWaidman ${ }^{21}$ defenderam que 0 acúmulo de função do ACS, além de fazer deste um novo profissional de saúde, o faz um profissional denível médio quepouco conhece de doença, pois é capacitado para disseminar conceitos de prevenção e saúde, divulgando mais informações sobre saúde do que sobre doença.

Atuação do fisioterapeuta

na atenção básica à saúde

As legislações relevantes sobre a atuação do fisioterapeuta na ABS são a COFFITO-10, que aprova o Código deÉtica Profissional ${ }^{29} \mathrm{em} 1978$; a COFFITO-80 em 1987, que complementa a COFFITO-8 e a COFFITO-3730 e a Resolução CNE/CES 4, que institui as Diretrizes Curriculares $\mathrm{N}$ acionais do curso de graduação em fisioterapia ${ }^{31}$ em 2002.

A Resolução COFFITO-1029 definecomo responsabilidade fundamental do fisioterapeuta prestar assistência ao homem, participando da promoção, tratamento erecuperação de sua saú- de e, como membro de uma equipe de saúde, participar de programas de assistência à comunidade, em âmbito nacional e internacional. $\mathrm{A}$ COFFIT 0-8030 também defendeestainserção em uma equipe de saúde ea atuação desse profissional nos diversos níveis de assistência à saúde com a mesma responsabilidade e com objetivos de preservar, promover, aperfeiçoar ou adaptar, através de uma relação terapêutica, o indivíduo a uma melhor qualidade de vida.

As Diretrizes Curriculare ${ }^{31}$ retomam essa capacidade deatuar em todos os níveis de atenção à saúde e reafirmam os objetivos defendidos pela COFFITO - $80^{30}$. Além disso, definem como competências e habilidades gerais desenvolver ações de prevenção, promoção, proteção e reabilitação da saúde, tanto em nível individual quanto coletivo e, no trabalho em equipe multiprofissional, estar apto a assumir posições de liderança, sempre tendo em vista o bem-estar da comunidade.

Freitas ${ }^{14}$, após análise minuciosa das resoluções do COFFITO, observou que não há referências concretas que apontem para a inserção da fisioterapia na ABS como campo detrabal ho, sendo isto definido com as Diretrizes Curriculares. Uma vez que as definições desta inserção são um fato recente, ainda se encontram al gumas dificuldades para uma legítima caracterização da atuação neste nível de atenção, como destacou Silva ${ }^{32}$ em seu trabalho sobre a fisioterapia na atenção básica do idoso. Entretanto, esse autor ${ }^{32}$ ressaltou que al gumas possibilidades de atuação se tornaram claras, já que alguns dos estudos revistos por eledefenderam objetivos semel hantes da fisioterapia nesta área de atuação, como a promoção da saúde e da qual idade de vida da população.

Em decorrência de al gumas características do trabal ho da fisioterapia na ABS serem diferentes das realizadas em outros níveis de aten ção à saúde, Freitas ${ }^{14}$ salientou que a profissão teve que agregar novos valores à sua prática e destacou algumas características dessa atuação: as intervenções são em domicílios, escolas, salões das UBS, igrejas, praças, etc.; 0 atendimento não é exclusivamente individualizado, incorporandose a este 0 atendimento em grupo; as ações são voltadas para a prevenção e promoção da saúde e a prática profissional é baseada em decisões coletivas, numa perspectiva interdisciplinar.

Este mesmo autor, em outro trabal ho publicado em 200033, Almeida et al. ${ }^{34}$ e Ragasson et al. ${ }^{35}$ destacaram que as contribuições dadas pelo fisioterapeuta podem ser tanto de forma interdisciplinar quanto específica e esta última em grupos ou de forma individual. 
Segundo Ragasson et al..$^{35}$, o fisioterapeuta, atuando de forma integrada à equipe, destina-se a planejar, implementar, controlar e executar políticas, programas, cursos, pesquisas ou eventos em Saúde Pública; de forma específica, contribui para a execução de ações de assistência integral às famílias em todas as fases do ciclo de vida: criança, adolescente, mulher, adulto e idoso, com o foco em atendimento domiciliar, pediátrico, direcionado à mulher e às patologias específicas eem atividades voltadas à terceiraidade e aos obesos.

Gallo ${ }^{36}$ fez referência às atribuições do fisioterapeuta na equipe, descritas por Ragasson et al..$^{35}$, e descreveu que a atuação deste profissional, em Londrina, édesenvolvida nos domicílios e nas UBS, e se volta para a visita e orientação fisioterapêutica aos indivíduos acamados, 0 atendimento pediátrico, a realização de ginástica laboral com os funcionários das U BS e para o atendimento em grupo detercei ra idade, diabéticose hipertensos.

Ribeiro ${ }^{1}$ e Almeida et al. ${ }^{34}$, ao descreverem experiências no "Projeto Fisioterapia na Comunidade", reafirmaram a participação de acadê micos de fisi oterapia de forma integrada à equipe de saúde em uma UBS e de forma específica. Ambos expuseram as diversas formas de atuação desenvolvidas: visitas e aten dimentos domiciliares, atendimento individual com foco na reabilitação, participação em grupos de gestantes, idosos, hipertensos e de coluna.

Nessa perspectiva, Ribeiro ${ }^{1}$ destacou o trabalho com grupos, que tem se mostrado como uma grande possibilidade de atuação da fisioterapia na ABS, representando uma das estratégias de aten der a uma grande demanda e a motivar à continuidade do tratamento; 0 atendimento domiciliar, como atividadeimprescindível no trabalho naABS, poisénesse nível de atenção quese depara com a realidade das pessoas; e a orientação postural, como o espaço de preven ção visando à manutenção da saúde.

No entanto, confessou que, apesar das atuações preventivas e educativas constituírem uma importante demanda, não conseguiam focar a atuação nessa perspectiva, pois dava-se prioridade aos atendimentos individuais e às visitas por existir uma maior demanda por esse tipo de atendimento. Tal fato também foi destacado por Trelha et al..$^{39}$.

Freitas ${ }^{33}$ também descreveu a atuação do fisioterapeuta integrada à equipe e de forma específica, defendendo a inserção do fisioterapeuta na ABS. Como ação específica, destacou o aten- dimento domiciliar e relatou que, além da utilização de recursos terapêuticos específicos, era estimulada a interven ção no meio em queo paciente vive, assim como abordagens educativas ao paciente e aos seus familiares.

Em seu trabalho derevisão, $\mathrm{Haas}^{37}$ expôs apenas a atuação específica do fisioterapeuta, destacando a intervenção em grupo e o atendimento domiciliar. Concluiu que este profissional pode atuar junto à população na prevenção, cura, reabilitação e na manutenção da integridade física.

Sampaio ${ }^{38}$, ao descrever a atuação de estagiários de fisioterapia em uma UBS, dividiu as interven ções desenvolvidas pela fisioterapia em dois tipos: programas, dirigidos a toda a comunidade e normatizados pelo MS ou pela Secretaria Municipal de Saúde, e serviços, voltados para o indivíduo ea família, e propostos deacordo com a demanda de cada Centro de Saúde. Dentre os programas, relatou a inserção da fisioterapia no de hipertensos, diabéticos e crianças portadoras de asma. Quanto aos serviços, atendiam à demanda espontânea com avaliações e tratamento individuais, atividades em grupo com pacientes portadores de patologias crônicas da coluna, atividade física para a terceira idade e para gestantes e visitas domiciliares.

Trelha et al. ${ }^{39}$ trouxeram relatos de fisioterapeutas, que caracterizaram sua atuação em assistência, educação, preven ção de doen ças eagravos, e promoção da saúde da população, atendendo de forma individual ou em grupo e por meio de visitas domiciliares.

Dentreas atuações dafisioterapiana ABS, Freitas $^{14}$ enfatizou queo atendimento domiciliar éuma característica comum e bastante presente. Ragasson et al..$^{35} 0$ descreveram como imprescindível ao fisioterapeuta, poiséo momento em quea realidade das pessoas é visualizada, a realização das atividades de vida diária e suas limitações são analisadas e os encaminhamentos e orientações são indicados. $\mathrm{E} \mathrm{Haas}^{37}$ citou que, ao chegar no domicílio, o profissional tem suas fronteiras de intervenção ampliadas, tendo a oportunidade de avaliar o ambiente onde o paciente reside, obter várias informações queauxiliam nasintervençõesterapêuticas adicionais, modificações ambientais eequipamento adaptativo. Ferreira et al ${ }^{40}$ destacaram que a presença naresidência al cança conhecimentos mais fidedignos do cotidiano familiar, o que torna a intervenção mais eficaz emais específica.

Segundo afirmou Freitas ${ }^{14}$, o trabal ho da fisioterapia possui um grande potencial mediador, podendo funcionar como um elo entre a comunidade ea equipe de saúde, favorecen do a identi- 
ficação dos problemas que devem ser considerados por toda a equipe na elaboração das ações de saúde.

$\mathrm{Hass}^{37}$ e Ragasson et al. ${ }^{35}$ enfatizaram a importância da presença deste profissional na ABS e sua contribuição para efetivar um sistema de saúde universal e equitativo, objetivando a promoção da saúde, prevenção de doenças, cura, reabilitação, manutenção da integridade física, educação continuada e a participação popular, sendo caracterizado por Ragasson et al..$^{35}$ como um agente multiplicador de saúde. Ainda neste contexto, Ferreira et al. ${ }^{40}$ defenderam quea atuação fisioterapêutica na comunidade obedece a Constituição Brasileira de 1988, artigo 196. Tal intervenção contribui para uma assistência integral e equânime, diminuindo ou prevenindo riscos à saúde, como defende esta lei. Também reafirmaram que a presença do fisioterapeuta na comunidade obedece aos princípios do atual modelo desaúde, tendo em vista que oferecesubsídios para a promoção, preven ção, recuperação e reabilitação e, consequentemente, promove a melhoria da qualidade de vida da população.

Agente comunitário de saúde e fisioterapeuta

Freitas ${ }^{14}$, ao fazer o relato de um caso, expôs que tal caso necessitou de uma maior participação de toda a equipe de saúde e destacou a atuação da agente comunitária como impulsionadora de todo o processo que envolveu a atuação interdisciplinar.

Este mesmo autor ${ }^{33}$, em 2000, descreveu que a eleição dos pacientes acamados, que seriam atendidos pelo projeto, era realizada a partir de uma listagem elaborada pelos ACS, que os identificava através de busca ativa em suas respectivas microáreas.

Gallo ${ }^{36}$ também descreveu que as visitas domiciliares da fisioterapia eram realizadas após uma triagem prévia dos ACS.

Em seu estudo, Sampai $0^{38}$ destacou que a contratação dos ACS possibilitou a ampliação da atividade de visita domiciliar realizada pelos acadêmicos de fisioterapia, pois os ACS faziam o levantamento dos casos e os discutiam com os acadêmicos e real izavam o acompanhamento dos pacientes e de seus familiares.

Ribeiro ${ }^{1}$ expôs que 0 treinamento de agentes comunitários e familiares para colaborar no processo de reabilitação representa uma en ormecontribuição para a evolução e eficácia do tratamento, além de favorecer a continuidade deste. Enfa- tizou que esse treinamento torna-se uma complementação que amplia as atividadese, possivelmente, confere mais qualidade ao tratamento.

Defendeu, também, que o fato do ACS conhecer a realidade social efamiliar do paciente em tratamento favorece a adequação dos procedimentos à disponibilidadee às necessidades dosindivíduos. Chegou a descrever a participação dos agentes como imprescindível, caracterizando sua colaboração tanto nas ações de reabilitação, quanto nas atividades educativas de caráter mais preventivo.

Esse mesmo autor ${ }^{1}$, ao relatar uma experiência profissional, colocou que os ACS elíderes comunitários favoreceram a inserção dos fisioterapeutas na comunidade. Ainda fez referência à atuação da fisioterapia em outra região, onde o atendimento domiciliar é complementado pelo monitoramento dos agentes, que observam as orientações dadas e acompanham o paciente no intervalo entre as visitas do fisioterapeuta.

\section{Discussão}

A maioria dos estudos destacaram a função do ACS e outros, a atuação do fisioterapeuta naABS; porém, poucos identificaram e relataram a interação das ações entre eles. Em relação à atuação profissional na ABS, a do ACS está melhor definida e descrita, comparada a do fisioterapeuta. $E$ os trabal hos que relataram experiências da atuação do fisioterapeuta trouxeram que este estava vinculado à UBS que implantava o PSF.

Verificou-se que há concordância entre os objetivos da atuação do fisioterapeuta descritos nos trabalhos e legislações. Em relação às atuações do ACS, também observou-se uma concordância, como foi descrito por Fabri eWaidman ${ }^{21}$, Silva ${ }^{26}$, Silva e Santos ${ }^{27}$.

Além disso, Nogueira et al. ${ }^{16}$, Fabri e Waidman $^{21}$ e Silva e Santos ${ }^{27}$ destacaram que as ações do ACS vão além do campo da saúde, sendo caracterizado por Nogueira et al. ${ }^{16}$ como um trabalhador sui generis. Há semel hança entreas descrições dos autores ao se referirem a uma característica peculiar e caracterizadora do ACS, a de estar entre a comunidade e a equipe de saúde, entreo saber popular eo científico, promovendo a integração entre eles. Através de diferentes denominações, os autores ${ }^{16-21}$ fazem alusão a esta característica.

Mas Nogueira et al. ${ }^{16}$ ainda ampliaram esta característica, destacando que o ACS possui um papel demediador social, resumindo-o como um elo entre os objetivos das políticas sociais do Es- 
tado e os objetivos próprios da comunidade, entre a capacidade de autoajuda própria da comunidade e os direitos sociais garantidos pelo Estado, entre o conhecimento popular e o conhecimento científico sobre saúde, entre as ne cessidades de saúde e outros tipos de necessidades das pessoas.

Bornstein eStotz ${ }^{17}$ concluíram queo papel de mediador do ACS é uma ideia comum, tanto no quese refereà mediação entre equipe ea comunidade como entre os diferentes saberes, o que está de acordo com o observado nesta revisão.

Como foi descrito por Freitas ${ }^{14}$, o papel de mediador também é uma característica da atuação do fisioterapeuta na ABS, pois quando este profissional entra no domicílio, tem um contato mais próximo com o paciente e a família, possibilitando a ampliação de suas ações e o conhecimento sobre a realidade em que se insere $o$ indivíduo, além de compartilhar essas informações com os outros profissionais da equipe.

A partir das atuações dos profissionais estudados nesta revisão, é possível destacar que atuam de forma interdisciplinar com a equipe de saúde da UBS e visam objetivos comuns: promoção da saúde, prevenção de doenças, contribuição para a melhoria da qualidade de vida da comunidadee integralidade da assistência. Também possuem atuações semel hantes, como a visita domiciliar, ações educativas eorientações com abordagem individual e coletiva, realizadas nos domicíliosena comunidade. Hácoincidência com relação ao público-alvo dos grupos, estando voltados principalmente para gestantes, puérperas, recém-nascidos, crianças, adolescentes, idosos, grupos de situação de risco ou de portadores de patologias crônicas.

Dentre as atuações, as direcionadas ao domicílio são destacadas como a principal atividade realizada por ambos os profissionais.

Fabri e Waidman ${ }^{21}$, Silva e Santos ${ }^{27}$ e a cartiIha referente ao $\mathrm{PACS}^{15}$ colocaram a visita domiciliar como a principal função do ACS. Da mesma maneira, 0 atendimento domiciliar foi destacado como de grande importância para a atuação do fisioterapeuta na ABS, por Freitas ${ }^{14}$, Ragasson et al. ${ }^{35}, \mathrm{H} \mathrm{aas}^{37}$ eFerrei ra et al. ${ }^{40}$. $\mathrm{O}$ contato com o usuário em seu domicílio foi enfatizado por todos esses autores como uma característica facilitadora da relação entre o profissional e 0 usuário/família, pois possibilita a aquisição de informações mais fidedignas do cotidiano familiar, tornando a intervenção mais eficiente. 0 contato mais próximo com o usuário é o que faz desses profissionais mediadores potenciais, pois prestam assistência integral ao indivíduo e mantêm uma relação interprofissional que fortifica o trabalho em equipe em uma UBS.

As ações do ACS que auxiliam a atuação do fisioterapeuta na ABS são a de acompanhar as famílias de sua respectiva microárea, orientá-las quanto à utilização dos serviços de saúde disponíveis na UBS, desenvolver ações que busquem sua integração com a população e desta com a equipe e identificar indivíduos ou famílias com necessidade de atendimento domiciliar e de grupos educativos.

0 vínculo que o ACS estabelece com a comu-

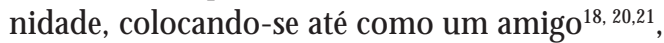
facilita ao fisioterapeuta a identificação de usuários que precisam deavaliação e/ou tratamento e a divulgação do serviço de fisioterapia prestado à comunidade, como foi descrito por alguns autores ${ }^{1,14,33,36,38}$ ao relatarem suas experiências em relação à atuação da fisioterapia na ABS.

A pesar de existir concordância entre as atuações descritas nas legislações e as realizadas na prática pelo ACS e pelo fisioterapeuta, alguns autores fizeram considerações quanto ao foco de atuação desses profissionais. Há discordância relacionada às ações realizadas pelo ACS: Silva e Santos ${ }^{27}$ eZancheta et al. ${ }^{28}$ relataram que as atividades têm um maior vínculo às doenças eFabri e Waidman ${ }^{21}$ descreveram que esse profissional é mais capacitado a divulgar conceitos de prevenção e saúde.

Diante do que foi descrito por Ribeiro ${ }^{1}$ eTre Iha et al..$^{39}$, relativo ao foco de ações, também se pôde constatar um desequilíbrio nas atuações do fisioterapeuta na ABS, já que as ações de prevenção possuem abordagem menor.

Então, a partir da revisão realizada e da abordagem em alguns trabalhos $\mathrm{S}^{1,7,14,35,37,40}$, verificouse que tanto o ACS quanto o fisioterapeuta são profissionaisimportantes na composição deuma equipe de saúde na $A B S$, pois contribuem para a qual ificação das ações de saúde junto à comunidadee a efetividade de um sistema de saúde universal, integral e equitativo.

\section{Consideraçõesfinais}

Conforme o propósito desta revisão, através da caracterização das ações próprias do agente comunitário de saúde e do fisioterapeuta na atenção básica à saúde, tanto em relação ao que é descrito nas legislações quanto nos trabalhos que destacam conceitos, observações evivências, identificamos a existência de ações semelhantes e 
complementares entre esses profissionais.

Desta forma, verificamos que há interface entre as atuações do agente comunitário de saúdee do fisioterapeuta, evidenciando que há uma interação entre esses profissionais e uma integração entre suas atividades, o que fortalece um preceito tão enfatizado nas definições de atenção básica, o trabalho em equipe.

\section{Colaboradores}

LF Loures eM CS Silva participaram igualmente de todas as etapas da elaboração do artigo.

\section{Referências}

1. Ribeiro KSQS. Fisioterapia na comunidade: buscando caminhos na atenção primária à saúde a partir de um projeto de extensão universitária [dissertação]. João Pessoa (PB): Universidade Federal da Paraíba; 2001.

2. Brasil. M inistério da Saúde. O SUS de A a Z. [site da Internet] [acessado 2007 mai 02]. Disponível em: http://dtr2004.saude.gov.br/susdeaz

3. Brasil. M inistério da Saúde. Cartilha Entendendo o SUS. [site da Internet] [acessado 2007 abr 14]. Disponível em: http://portal.saude.gov.br/portal/ arquivos/pdf/cartilha_entendendo_o_sus_2007.pdf

4. Brasil. Portaria no $\overline{6} 48$ de 28 de março de 2006. Dispõe sobre a aprovação da Política Nacional de Atenção Básica, estabelecendo a revisão de diretrizes e normas para a organização da Atenção Básica para o Programa Saúde da Família e o Programa Agentes Comunitários de Saúde. Diário Oficial da União 2006; 28 mar.

5. Brasil. M inistério da Saúde. Atenção Básica e a Saúde da Família. [site da Internet] [acessado $2007 \mathrm{abr}$ 14]. Disponível em: http://dtr2004.saude.gov.br/ dab/atencaobasica.php

6. Poz M RD. 0 agente comunitário de saúde: algumas reflexões. Interface (Botucatu) 2002; 6(10):75-94.

7. Brasil. M inistério da Saúde. M odalidade de contratação de agentes comunitários de saúde: um pacto tripartite. [site da Internet] 2002 [acessado 2007 mai 22]. Disponível em: http://dtr2001.saude.gov.br/ editora/produtos/livros/pdf/02_0240_M.pdf

8. Brasil. M inistério da Saúde. Saúde da Família: uma estratégia para a reorientação do modelo assistencial. 1997 [site da Internet] [acessado 2007 mai 22]. Disponível em: http://bvsms.saude.gov.br/bvs/publicacoes/ cd09_16.pdf

9. Brasil. M inistério da Saúde. Referencial curricular para curso técnico de agente comunitário de saúde: área profissional saúde. [site da Internet] 2004 [acessado 2007 mai 22]. Disponível em: http://bvsms. saude.gov.br/ bvs/publicacoes/referencial_Curricular_ACS.pdf

10. Brasil. Portaria no 1.886 de 18 de dezembro de 1997. Dispõe sobre a aprovação das normas e diretrizes do Programa de Agentes Comunitários de Saúde e do Programa de Saúde da Família. Diário Oficial da União 1997; 18 dez. 
11. Brasil. Decreto no 3.189 de 4 de outubro de 1999. Dispõe sobre a fixação das diretrizes para o exercício da atividade de agente comunitário de saúde e dá outras providências. Diário O ficial da U nião 1999; 04 out.

12. Brasil. Lei no 10.507 de 10 de julho de 2002. Dispõe sobre a criação da profissão de agente comunitário de saúde e dá outras providências. Diário Oficial da União 2002; 10 jul.

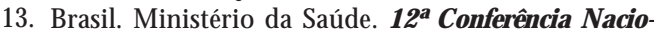
nal de Saúde: Conferência Sérgio Arouca. Relatório Final. [site da Internet] 2004 [acessado 2007 nov 15]. Disponível em: http://www.conselho.saude.gov. br/biblioteca/Relatorios/relatorio_12.pdf

14. Freitas MS. A Atenção Básica como campo de atuação da fisioterapia no Brasil: as diretrizes curriculares re significando a prática profissional [tese]. Rio de Janeiro (RJ): Universidade do Estado do Rio de Janeiro; 2006

15. Brasil. M inistério da Saúde. Programa agentes comunitários de saúde (PACS). [site da Internet] 2001 [acessado 2007 mai 22]. Disponível em: http:// bvsms.saude.gov.br/bvs/publicacoes/pacs01.pdf

16. Nogueira RP, Silva FB, Ramos ZVO. A vinculação institucional de um trabalhador "sui generis": 0 agente comunitário de saúde. Texto para discussão n 735 [site da Internet] 2000 [acessado 2007 maio 24]. Disponível em: http://www.ipea.gov.br/pub/td/ td 2000/td0735.pdf

17. Bornstein VJ, Stotz EN. Concepções que integram a formação e o processo de trabalho dos agentes comunitários de saúde: uma revisão da literatura. Cien Saude Colet 2008; 13(1):259-268.

18. Nunes M O, Trad LB, Almeida BA, Homem CR, M elo M CIC. $O$ agente comunitário de saúde: construção da identidade desse personagem híbrido e polifônico. Cad Saude Publica 2002; 19(6):1639-1646.

19. Silva IZQJ, Trad LAB. 0 trabalho em equipe no PSF: investigando a articulação técnica e a interação entre os profissionais. Interface (Botucatu) 2004/ 2005; 9(16):25-38

20. Levy FM, Matos PES, Tomita NE. Programa de agentes comunitários de saúde: a percepção de usuários e trabalhadores da saúde. Cad Saude Publica 2004; 20(1):197-203.

21. Fabri CA, Waidman MAP. Visita domiciliar: a atividade do agente comunitário de saúde no programa saúde da família. Fam Saúde Desenv. 2002; 4(2):106-118.

22. Friedrich DBC, Pierantoni CR. 0 trabalho das equipes da saúde família: um olhar sobre as dimensões organizativa do processo produtivo, político-ideológica e econômica em Juiz de Fora. Physis 2006; 16(1):83-97.

23. Fortes PAC, Spinetti SR. A informação nas relações entre os agentes comunitários de saúde e os usuários do programa de saúde da família. Saude soc. 2004; 13(2):70-75

24. Ferraz L, Aerts DRGC. O cotidiano de trabalho do agente comunitário de saúde no PSF em Porto Alegre. Cien Saude Colet 2005; 10(2):347-355

25. Pedrosa JIS, Teles JBM. Consenso e diferenças em equipes do Programa Saúde da Família. Rev. Saude Publica 2001;35(3):303-311.

26. Silva ABF. A supervisão do agente comunitário de saúde: limites e desafios para a enfermagem [dissertação]. Ponta Grossa (PR): Universidade Estadual de Ponta Grossa; 2002.
27. Silva M HS, Santos M R. Perfil de atividades dos agentes comunitários de saúde vinculados ao Programa de Saúde da Família da zona norte de Juiz de Fora. Rev. APS [periódico na Internet]. 2005 [acessado 2007 set 19]; 8(2): [cerca de 18 p.]. Disponível em: http://www.nates.ufjf.br/novo/revista/v008n2.htm

28. Zanchetta $M$, Leite $L$, Perreault $M$, Lefebvre $H$. Educação, crescimento e fortalecimento profissional do agente comunitário de saúde - estudo etnográfico. Online braz. j. nurs. [periódico na Internet]. 2005 [acessado $2007 \mathrm{mar}$ 27];4(3):[cerca de 13 p.]. Disponível em: http://www.uff.br/objnursing/ viewarticle.php?id=74

29. Conselho Federal de Fisioterapia e Terapia Ocupacional. Aprovação do Código de Ética Profissional de Fisioterapia e Terapia Ocupacional. Resolução COFFITO-10 de 3 de julho de 1978. Disponível em: http://www.coffito.org.br

30. Conselho Federal de Fisioterapia e Terapia Ocupacional. Complementação da COFFITO-8 e COFFITO-37 e outras providências. Resolução COFFITO-80 de 9 de maio de 1987. Disponível em: http:/ /www.coffito.org.br

31. Brasil. Resolução CNE/CES 4 de 19 de fevereiro de 2002. Diretrizes Curriculares Nacionais do Curso de Graduação em Fisioterapia. Disponível em: http:/ /portal.mec.gov.br/cne

32. Silva APG. A fisioterapia na atenção primária do idoso: uma revisão da literatura [dissertação]. Franca (SP): U niversidade de Franca; 2005.

33. Freitas MS. A Fisioterapia na Atenção Primária à Saúde em Juiz de Fora. In: Barros FBM, organizador. 0 fisioterapeuta na saúde da população: atuação transformadora. Rio de Janeiro: Fisiobrasil; 2000.

34. Almeida $A B$, Oliveira AMB, Ribeiro KSQS. A fisioterapia na atenção básica a partir de uma experiência de educação popular. In: Anais do V Colóquio Internacional Paulo Freire; 2005; Recife.

35. Ragasson CAP, Almeida DCS, Comparin K, M ischiati M F, Gomes JT. Atribuiç̧ões do fisioterapeuta no programa de saúde da família: reflexões a partir da prática profissional. [site da Internet] [acessado 2007 mai 11]. Disponível em: http://www.crefito5.com.br /web/downs/psf_ado_fisio.pdf

36. Gallo DLL. A fisioterapia no Programa Saúde da Família: percepções em relação à atuação profissional e formação universitária [dissertação]. Londrina (PR): Universidade Estadual de Londrina; 2005.

37. Haas D. A evolução da assistência a saúde pública no Brasil e a interação da fisioterapia no contexto atual [trabalho de conclusão de curso]. Cascavel (PR): Universidade Estadual do Oeste do Paraná; 2003.

38. Sampaio RF. Promoção de saúde, prevenção de doenças e incapacidades: a experiência da fisioterapia/UFMG em uma unidade básica de saúde. Fisioter M ov.2002; 15(1):12-23.

39. Trelha CS, Silva DW, lida LM, Fortes MH, Mendes TS. 0 fisioterapeuta no programa de saúde da família em Londrina (PR). Espaç. saúde 2007; 8(2):20-25.

40. Ferreira FN, Leão I, Saqueto $M B$, Fernandes $M H$. Intervenção fisioterapêutica na comunidade: relato de caso de uma paciente com AVE. Rev Saúde Com. 2005; 1(1):35-43.

Artigo apresentado em 02/01/2008

Aprovado em 27/06/2008 